\title{
The perception of the family health team concerning their support to breastfeeding
}

\author{
Percepção da equipe de saúde da família sobre o apoio ao aleitamento materno \\ Percepción del equipo de salud familiar acerca del apoyo a la lactancia materna
}

Monika Wernet ${ }^{1}$, Márcia Regina Cangiani Fabbro ${ }^{1}$, Karina Rumi de Moura ${ }^{1}$, Daniela Aparecida Salgado Targino ${ }^{1}$, Viviane Pompeu ${ }^{1}$, Aline Oliveira Silveira ${ }^{2}$

This study aimed at characterizing how two teams of 22 subjects of the Family Health of a city in São Paulo, Brazil, observe its process to protect, promote and support exclusive breastfeeding. The theoretical framework was the Symbolic Interactionism and the methodological one and the Thematic Content Analysis. The focus group was a resource for data collection which occurred between February and May 2011. The results were categorized into: "Obligation to promote exclusive breastfeeding", "Autonomy of the mother" and "Personal experience and professional practice". We conclude that the teams follow the guidelines for promotion and support of breastfeeding, they identify that the autonomy of the mother is determinant for the practice, integrating and respecting how each woman breastfeeds. They believe they are effective in promoting and supporting breastfeeding and conceive the relevant international protocols, but need to be incorporated with flexibility in the everyday life.

Descriptors: Breast Feeding; Family Health; Patient Care Team.

Objetivou-se caracterizar como 22 sujeitos de duas equipes de Saúde da Família de cidade paulista brasileira percebiam o processo de proteger, promover e apoiar o aleitamento materno exclusivo. 0 referencial teórico foi Interacionismo Simbólico e o metodológico, Análise de Conteúdo Temática. 0 grupo focal foi recurso para coleta de dados, ocorrida entre fevereiro e maio de 2011. Os resultados foram categorizados em: "Obrigatoriedade em promover o aleitamento materno exclusivo", "Autonomia da mãe" e "Experiência pessoal e prática profissional". Concluiu-se que as equipes pautavam-se nas diretrizes para promoção e apoio do aleitamento, identificavam ser a autonomia da mãe determinante para a prática, integrando e respeitando a forma como cada mulher aleita. Estas se julgavam efetivas na promoção e no apoio ao aleitamento materno e concebiam os protocolos internacionais relevantes guias, porém estes necessitam ser incorporados com flexibilidade no cotidiano.

Descritores: Aleitamento Materno; Saúde da Família; Equipe de Assistência ao Paciente.

El objetivo fue caracterizar como 22 participantes de dos equipos de Salud Familiar de cuidad paulista brasileña percibían el proceso de proteger, promover y apoyar la lactancia materna exclusiva. El marco teórico fue el Interaccionismo Simbólico y el metodológico, el Análisis de Contenido Temático. El grupo focal fue el recurso para la recolección de datos, ocurrida de febrero a mayo de 2011. Los resultados fueron categorizados en: "Obligación en promover la lactancia materna exclusiva”, "Autonomía de la madre” y “ Experiencia personal y práctica profesional”. En conclusión, los equipos son guiados por directrices para promover y apoyar la lactancia materna, identificaban la autonomía de la mujer determinante para la práctica, integrando y respetando la forma como mujer amamanta. Estas se juzgaban efectivas en la promoción y apoyo a la lactancia materna y concebían los protocolos internacionales pertinentes guías, pero necesitaban ser incorporados con flexibilidad en la vida cotidiana.

Descriptores: Lactancia Materna; Salud de la Familia; Grupo de Atención al Paciente.

\footnotetext{
${ }^{1}$ Universidade Federal de São Carlos. São Carlos, SP, Brazil.

${ }^{2}$ Universidade de Brasília. Brasília, DF, Brazil. 


\section{Introduction}

The benefits of maternal breastfeeding ${ }^{(1)}$ in a short and long term range are described and determine its priority in the agenda of the child maternal policies of health ${ }^{(2)}$. According to that, efforts for its promotion, support and protection are present in the several levels of health care $^{(1-3)}$. However, the basic health care presents differentiated potentiality in the incentive of this practice, as well as the identification and early intervention on the risks and difficulties along the same ${ }^{(3)}$. Within this scope is the Family Health Strategy, a model of health care that has as differential the promotion in health by a multi professional team with emphasis in the autonomy of the subjects, in the participative planning and in the partnership among the sectors ${ }^{(4)}$. The Family Health Strategy in Brazil is an assistance model of current investment.

The World Health Organization, the United Nations Children's Fund and the Health Department in Brazil preconize that every child must be exclusively breastfed with maternal milk from birth until six months of age and, after this period, the newborn must go on and being breastfed, together with complementary food until two years of age or more ${ }^{(5)}$. Exercising the practice of maternal breastfeeding promotes a link, affection, protection and nutrition for the child, with significant impacts in his development and in the reduction of the child morbidity/mortality ${ }^{(6)}$.

According to the above mentioned, the team of the Family Health Strategy is an important nucleus in the practice of maternal breastfeeding. But the effectiveness of their actions depends on the capacity and ability of the health professional in listening, stablishing a link, being sensitive to the needs of each family ${ }^{(7)}$, as well as taking mutual contextualized decisions. The improvement of the rates of maternal breastfeeding in Brazil can have, in the support of the health professional, a differential, especially those of the basic health care and the Family Health Strategy.

Therefore, the present study adopted the following question: 'How do the teams of Family
Health Strategy support the practice of maternal breastfeeding?' The objective was to characterize how the team of Family Health Strategy perceives their process of protecting, promoting and supporting the practice of the maternal breastfeeding.

\section{Method}

This is a qualitative research which used as theoretical reference the Symbolic Interactionism. This is focused on the human actions, regarding how the meanings emerge, how they are manipulated and altered in the social interaction ${ }^{(8)}$.

Their premises are three: (1) the manner how the human being interprets the facts and behaviors facing someone or something, depends on the meaning that he imputes to the elements present in this context; (2) the meaning that the human being attributes to someone or something is a result of the processes of a social interaction or are constructed from such elements; (3) the meanings that the human being gives to someone or something are modifiable ${ }^{(8)}$.

In order to apprehend the objective in this research and, in consonance with the theoretical reference selected, the Bardin's Thematic Content Analysis is a pertinent methodological reference. The Content Analysis is a method which covers a set of techniques of analysis and that, through systematics procedure, allow the comprehension of the product of the communication ${ }^{(9-10)}$.

In order to serve the proposed objective, the technique of focus group was selected for data collection $^{(11)}$. It was decided to make the study with two teams of the Family Health Strategy of a city in the countryside of São Paulo, Brazil. The selection of the teams had as criterion the indicated of exclusive maternal breastfeeding of the County Health Department, choosing the highest and the lowest rate in the year of 2009.

Twenty two health professionals, distributed in two teams integrated the study. Two focus groups were developed with each team along the 
months of February to May 2011. The reports were recorded in audio (the total recording time was 170 minutes) and later on whole transcript to suffer the analytical processes preconized by the method of thematic content analysis ${ }^{(9)}$. The conduction of the analysis involved systematic stages, as follows: the data codification, the data categorization, and the integration of the thematic nuclei ${ }^{(9)}$. Its start occurred with reiterative readings of the transcript of the focus groups, searching for the identification of the conceptions of the team concerning the support to maternal breastfeeding, to analyze and integrate such data in thematic categories presented later on.

In order to preserve the anonymity of the subjects and team, it was chosen to identify sections of the focus group with a word team followed by the number of the order in which they integrated the study. So, team 1 was the first one to be inserted in the study and team 2, the second. It is highlighted that what was apprehended in the study describes the way how the team conducts its support to the practice of maternal breastfeeding, which determined the choice of not identifying the professional category of the sections of the report.

This study followed the recommendation for researches involving human beings with the approval of the Committee of Ethics Team Research with Human Beings of the Universidade Federal de São Carlos through ordinance no. 267/2010.

\section{Results}

The 22 participants of the research were mostly women (19 women and 03 men), all the men were fathers, and of the 19 women, 16 were mothers. Regarding the age, 3 people were older than 45 years, 7 people between 40 and 45 years, 7 people between 30 and 35 years, and 5 people between 25 and 30 years. As to the professional category, 2 were nurses, 2 doctors, 2 dentists, 2 dentist assistants, 3 nurse assistants and 11 were health communitarian agents. The analysis of the data allowed the appre- hension of the experience of two teams of the family health strategy in the approach of exclusive maternal breastfeeding. From the analyzed material three thematic categories emerged: It is mandatory to promote exclusive maternal breastfeeding; Autonomy of the mother and personal experience and professional practice.

The mandatory thematic category in promoting exclusive maternal breastfeeding pictures the process experienced by the team in the sense of developing in its assistance everyday activities the world and national protocol recommendations for the consummation of exclusive maternal breastfeeding until the sixth month of life. All the actions come from the responsibility that the team takes for itself in order to guarantee and promote the exclusive maternal breastfeeding. That is, it is centered in the search of the errors in the process and develops its interaction based on the appointment of the same and in the offer of orientations on what the protocols consider adequate for the practice.

Among the surveillances of major concern is linked to the early introduction of the milk bottle. Symbolically, milk bottles represent for the team a relevant deviation and, in a certain way, links such fact to the effectiveness or not of its interventions, thus the sensation of failure. The health professionals became very disappointed with this event and, as a reflect of this conception, many of the orientations are concentrated in the disadvantages of the introduction of the milk bottle, having no room to explore feelings and experiences of the women and families when introducing the milk bottle and how much it is an obstacle, in the reports of the nursing mothers in a dialog with the health professionals: ... when we perceive or see that the milk bottle was used, we get disappointed. It seems that everything we did was worthless. It is a defeat. Afterwards we recover and know that this happens and that it does not depend only on us, but yes, it is a failure (Team 1).... So, it depends a lot on our routine to have a look at the child, maybe she is having a problem, if the mother's nipple is chapped, if she is using the milk bottle (Team 1).

However, it is identified that the team tries 
to make use of all the interactional spaces to make their interventions in favor of the exclusive maternal breastfeeding, with prevalence of the formal moments foreseen in theagenda of the assistance of thepregnant/ puerpera, that is, the pre-natal and puerperium appointments, the home visits and the group of the pregnant woman. But other aspects are identified as powerful and some professionals use them widely. These are mentioned examples: the moment of the collection of the neonatal screening (phenylketonuria exam) or the foot exam (a laboratory exam which detects more than 45 metabolic and genetic different diseases), the moment of vaccination, the activities of the baby tooth program and informal conversations in the hall or in the waiting room: when we collect the PKU we already ask if she is breastfeeding, then we ask the technique she uses, if she has the breast full or if she is not managing to breastfeed (Team 1). With the new schedule of vaccination the child has to come and we use the opportunity to ask and orientate (Team 1).

They highlight that supporting and promoting maternal breastfeeding in the medical and nursing appointments requires counting on the complete team, once such action requires time and it is unpredictable of how much such act will last. With this, they report to be inevitable to develop the intervention with quality when the team lacks someone, especially when this lack is a doctor or a nurse. When we are without a doctor or a nurse it is unfeasible to provide care and the necessary orientation. We do what we can, but with different quality. The time we have is reduced (Team 2 ).

The process of support and promotion of exclusive maternal breastfeeding receives a differentiated investment in the week that is worldwide destined to the theme. They report that there is a greater mobilization of the team when they get involved with the theme, especially through the rescue and updating regarding what the protocols and guidelines are recommending. ... In the week of breastfeeding we discuss where to act more and the strategies, where to focus and where to resume the concepts ... We review what the World Health Organization and United Nations Children's Fund are saying and then we update our work (Team 1).
In addition, the team invests and worries enhancing their knowledge on maternal breastfeeding, which determines a stimulus for the presences and capacitation offered by the county, as well as the use of the team meetings for the discussion of the thematic, both in a theoretical manner as well as through the discussion of existing cases in their domain. With capacitation, the health professionals and their team feel more secure and speak with more scientific property on the subject with their uses, always in accordance with the organizational recommendations. ... Once here everyone took the breastfeeding course, everyone knows what they say and how they say it. Everyone knows what is recommended and how to do it. I think that there is not anyone who did not take the course, who does not what is to be done, what the World Health Organization says (Team 1).

They recognize that everyone in the team must know and be united in favor of breastfeeding, with similar and congruent conducts and speeches. And, in this sense, the conception of being the ones who know about the theme appears clearly and with this they must direct, determine and watch the actions of the mothers in this respect. This manner of thinking and acting, we, health professionals, are the ones who have the knowledge, having our roots in the education itself of the health professional, anchored in the biomedical paradigm which is fed back in the professional practice when the orientations are passed on to the client, comprehending the subject as an empty box which needs to filled ${ }^{(12)}$. A good aspect is that everyone has this look tuned to maternal breastfeeding to provide support and promotion. We speak the same language, we tell them what to do the same way, we orient quite similarly (Team 2).

The thematic category Autonomy of the mother brings as central purpose, the identification by part of the team that the mother is the one who will have the option for the practice of maternal breastfeeding and how it will be developed. And, in that sense, they establish, along their actions, the perception that the team is a support for such action and/or option, but the final decision belongs to the mother.

Under the conception of the team, the mothers, 
to assume exclusive maternal breastfeeding, need to have will power to comply with the protocol required and recognize it as it is the best there is, both for her as for the child, that is, she must be aware of the benefits breastfeeding brings for both. She tried everything, straws, milking, everything. Until the day she managed it and she was very happy. I think the will of the mother is much more important than any other thing or orientation (Team1). The first thing is the perception of the mother that this (breastfeeding) is the best. If the mother does not have this, I do not know if it would be possible. I don't really know (Team 2).

They also perceive the influence of the pleasure of the mother in breastfeeding. The team states that the dedication required, the overcoming of the difficulties occur when the mothers have already incorporated that breastfeeding is something that brings pleasure, which satisfies expectations built in the prospection of the act of breastfeeding and being a mother. When this pleasure is aggregated to the act of breastfeeding, the process can flow more easily. However, when the maternal breastfeeding does not bring pleasure (on the contrary, it brings suffering, pain, frustration and guilt), the conditions to settle down in the I-woman-mother, and the I-womannursing mothers are reduced, and many times it is difficult to reverse weaning.

The reports below review that the process of breastfeeding and the experience as a privation of being able to take care of herself and places the woman in the condition to completely serve the child, which can generate many internal conflicts and many times external ones (with the family and with the health professionals) after all, with society, once this role of total and unconditional donation is expected. ... And the mother turned and said: look well at me. Look at this hair, look at my nails, look at my condition... I can't do anything anymore! This child just keeps breastfeeding, breastfeeding, breastfeeding... I can't stand any longer, it's difficult, I don't want it, it's no good, it's doing me no good (Team1). The ones who breastfeed, breastfeed because they like to breastfeed, they feel well. We can see pleasure in their eyes, the loving for breastfeeding ... (Team 2).

Another aspect considered by the team is the wish to be a mother and breastfeed. They report that when pregnancy was planned and expected, normally it is more common that breastfeed happens than when they were not. They believe that breastfeeding is an option of the mother, but that this option, to be made in a more concise and peaceful manner needs time, and incorporation of this act in the 'I' of the woman. If it is something planned, and she was expecting, I think it is easier ... It seems that there is more time to think, to reflect and to decide. Breastfeeding is a decision, it's to look here and there and say: I want this (Team 2).

In this choice of the woman concerning maternal breastfeeding, the team highlights the family as a nucleus which disseminates concepts. And, within this nucleus, the grandmother is highlighted, especially the maternal grandmother, for having a central role, for being perceived as the person who carries the experience within herself. Ah... there is also the influence of the family; my mother used to do this... there is a lot of that. We noticed that it influences in her decision, it's a parameter that she uses. From her mother then, it weights a lot more (Team 1).

The team recognizes that breastfeeding is a social act and, therefore, the beliefs on the same are common whichever the context which the family is inserted in. The team chooses to administer the interaction of the maternal breastfeeding with the beliefs. In this study, the teams reported that the following conceptions are quiet present: 'maternal milk is weak', 'the child needs water', 'only maternal milk does not quench thirst', 'maternal milk does not nourish', ' tea is needed for the colic', 'a healthy baby is fat' and 'they stole my milk'. It's better for her to give tea and breastfeed and look for us the next time than for me to cut, she gives the tea in the same manner and she doesn't come here anymore (Team 1).

Facing these conceptions, the team feels limited in the transformation of the same, once it is only risking breastfeeding that the mother would prove not to be like that. It is abstract to say that she will see the positive results beforehand, only through the offer of orientation. The even tried to make use of examples of their land, but the mother lived along his history of life 
with the reinforcement of certain conceptions. These beliefs historically reinforced and transmitted are the most difficult to deal with and the team, at times, do not even try to modify them. She already places herself in the condition of rendered, or at the most, they try to negotiate the breastfeeding with other historically inherited practices. So, the teams try to respect the particularities and context of each mother and they opt for not denying the belief, but they try to integrate maternal breastfeeding to the practice of feeding the child.

Facing the negative of some mothers to breastfeed, the team reported to feel: frustration, sadness, deception and indignation. They recognize and know that, despite all the effort of the team, the autonomy of the mother is still what prevails in the decision. I become very indignant, especially because I worked, incentivized, explained ... (Team 2). When I see someone telling me that she'll no longer breastfeed I have a feeling of sadness (Team 1).

In the category Personal thematic experience and professional practice, the recognition by the team that the adoption of their personal experiences is explicit, both as nursing mothers, as well as the ones historically transmitted, are present in the action developed in favor of maternal breastfeeding. The health professional use the experiences to reflect and decide how they will lead each situation where the exclusive maternal breastfeeding is under consideration. They integrate their experiences to the protocol knowledge acquired on the theme to assist their uses. They also value the opinions of the participants of the team who are already fathers or mothers when they discuss the conduction of situations which involve maternal breastfeeding.

In addition, the health professionals themselves who have paternal experiences feel differentiated for conducting such situations. They report to have the sensitivity of listening and reflection on what was exposed and a greater creativity to decide behaviors. I saw how important it was for me to breastfeed; today I use this when I talk with the mothers about breastfeeding. We become different, it seems we know more, it seems we manage to have more ideas, give options (Team 1).

Even the negative experiences are valued by the team and considered relevant to discuss and conduct situations which involve obstacles with maternal breastfeeding. I didn't have any patience to remain seated in order to breastfeed, it was horrible, I knew I should breastfeed, but in that position, quiet, it was no good. Not even because of that I stopped to breastfeed. Today I use this experience in my care (Team 2).

Sharing the experiences of the member of the team regarding the process of exclusive breastfeeding contributed for the team to realize that she searches for the accomplishment of exclusive breastfeeding, but this practice depends on concepts which are not established in distinct interactional areas, being the ones who had experience with the team one kind of many. With that, they feel effective and active within the environment they are always in the pursuit of offering opportunities of re-significance in favor of exclusive maternal breastfeeding. There is no right or wrong, there is what is better. This we learned here, listening to our own stories (team 2).

\section{Discussion}

The study reviewed aspects which structured the support to maternal breastfeeding by part of the team, and we can affirm that there is a movement for a dialogical practice centered on the tripod subject, family and community, which is hindered when the protocols lead the team to invert its relational logic. The technical rationality many times invades the communicative rationality and creates barriers to the process of construction of dialogical practices.

The teams recognize the importance of supporting maternal breastfeeding from the social context of the mothers and family, but they adopt the recommendations of recognized entities such as the maximum guideline and, with this, they adopt an interaction based on the professional and user hierarchy and develop a disciplinarian role. Concerning the health professional/practice in health relation, the identity of the professional has 
been constructed between the inseparable relation who is established in the professional domain with other social cultural universes ${ }^{(13)}$ and it will directly influence in their actions in favor of breastfeeding, as shown in the results.

Still analyzing this context, it is not sufficient for the situation to have a formative potential. It is also necessary, that the situation makes some sense, so that the professional uses the theoretical knowledge looking forward his implications in the practice ${ }^{(14)}$. In the present research, it is possible to affirm that the teams are experiencing this, but with an incorporation that does not yet allow them to start a dialogical care, which can be against the protocol, once breastfeeding is a social practice. This was also pointed out in this revision ${ }^{(15)}$ which showed the need to overcome the biologist and decontextualized vision of the care rendered to the nursing mother and her family, which implies in considering the specificity of the experience and in a certain way break, with the literal adoption of recommendation of guidebooks and protocols, practicing creativity and dialogue in the interventions of health.

Maternal breastfeeding as social practice is permeated by the beliefs and the ones found in the present study, 'weak milk', 'which does not nourish' and the child 'starves' confirm with the ones mentioned in other researches on the thematic ${ }^{(16-17)}$. The recurrence of beliefs in the researches shows the relevant to understand them and reflect on the fact that the axis of the orientation is what must structure the available support in this context.

In this sense, the professionals are in the domain of external influences and, rethinking how they weave the relation with users and family, having as reference a relation of horizontality and respect, can be an important tool to overcome the culture of superiority of the actions of health, especially, the ones related to the practice of breastfeeding, supported by the paradigm that the word of the health professional is the absolute truth. So, it can show a way, so that the professionals can be part of the nuclei of confidence and security of the nursing mothers and their families and build domains of consensual decisions.

The autonomy of the mother and family in the act of breastfeeding is present in several researches and reinforces the fact that the decision of the details which permeate such act belong to the woman/ mother ${ }^{(18,17)}$. However, a true autonomy means that the nursing mothers can have access to information, a dialog with other women and health professionals, in order to identify the obstacles and transforming aspects which help in the taking of decision of breastfeeding or not, making use of her right of election and autonomy on her body.

Facing this scenario and the results obtained, it was perceived that the health professionals develop their practices of care under the coercion of the protocol, but with clear consciousness of knowing that breastfeeding is autonomous social practice. The teams in this study experienced a hybrid position in their daily lives, where, at the same time, they adopt the logic of the work (I am a health professional) and the logic historical subject (I am the subject who shared/experienced maternal breastfeeding). They experienced the conception of being contradictory to integrate the two logic in his duty, however, it is integrating these logics that they support the practice of the same in their domains of coverage. So, they are classified as efficient and non-efficient, as if facing a social practice such classification could exist. The indicators of health and the assistance and curative model still imprison creativity and the actions of the team, because they are centered in the logic of the existence of only one result. Because of that, the maternal breastfeeding thematic can make the professional disbelieve in investments.

The dialogic perspective is a way to face the mismatch between the health professional and the users $^{(19)}$ and, in this sense, the evidence of this research portrait how much the team wants to go along this way, however, it experiences the charges of the indicators, which inhibited and tend to dislocate its movement of care for the logic of vigilance and orientation. So, we 
suggest the development of other researches which specifically explore this focus, once we understand that they can contribute for a transformation of this scenario.

In addition, we suggest the development of researches that integrate distinct strategies of data collection, in order to have the present study, the limit of adoption of the focus group. Researches which adopt strategies and which are close to the professional duty could enhance and densify the evidences here unveiled

\section{Conclusion}

This study concluded that the teams feel they are capable of promoting and supporting maternal breastfeeding when using the protocols as a guide for their clinical practice. However, they need to be aware that this incorporation must be made with the flexibility proper of the everyday practice, considering the liberty of election of each woman/family and the fact that each one is different. Therefore, the teams must use, in a more operational and efficient manner the assistance post-partum, based on the guides endorsed by the competent organs, but understanding that the freedom of election of the nursing mother is what supports this practice, that is, the actions of each woman in particular.

Promoting, protecting and supporting maternal breastfeeding under a dialogical perspective, which impact in the rates of maternal breastfeeding, require much more than welcoming words and technical ability. The social practice instigates to review the pre-concepts and the practices of health protocoled by technical guides.

Is it possible to completely accept a mother who refuses to breastfeed? Is it possible to provide advice or use 'mandatory suggestion' with the nursing mothers? Is it possible that listening is really exercised?

The empowerment of the nursing mother/ family in the process of breastfeeding cannot be seen as a delegation of decision. It must be conceived as a process of acquisition of elements to make choices, informed and dialogued decisions, free of impositions, that is, present all the options and give freedom of choice to the person.

\section{Acknowledgments}

To the County Department of Health of São Carlos, SP, Brazil for the authorization for the making of the research and to the teams of the Family Health Strategy who accepted to participate in in the investigation.

\section{Collaborations}

Moura KR and Pompeu V contributed for the conception of work, collection and data analysis. Fabbro MRC, Silveira AO and Targino DAS collaborated for the interpretation of data and writing of the article. Wernet M contributed for the orientation, writing of the article and for the final approval of the version to be published.

\section{References}

1. Ministério da Saúde (BR). Secretaria de Atenção à Saúde. Departamento de Ações Programáticas e Estratégicas. Além da sobrevivência: práticas integradas de atenção ao parto, benéficas para a nutrição e a saúde de mães e crianças. Brasília: Ministério da Saúde; 2011.

2. Gomes MA. As políticas públicas na área de saúde da criança. Cienc Saúde Coletiva. 2010; 15(2):3286.

3. Pereira RSV, Oliveira MIC, Andrade CLT, Brito AS. Fatores associados ao aleitamento materno exclusivo: papel do cuidado na atenção básica. Cad Saúde Pública. 2010; 26(12):2343-54.

4. Scherer MDA, Pires DEP, Jean R. A construção da interdisciplinaridade no trabalho da equipe de saúde da família. Ciênc Saúde Coletiva. 2013; 18(11):3203-12. 
5. Ministério da Saúde (BR). Secretaria de Atenção à Saúde, Departamento de Atenção Básica. Saúde da criança: nutrição infantil: aleitamento materno e alimentação complementar. Brasília: Ministério da Saúde; 2009.

6. Ministério da Saúde (BR). Secretaria de Atenção à Saúde. Departamento de Ações Programáticas e Estratégicas. Pesquisa de prevalência de aleitamento materno nos municípios brasileiros. Brasília: Ministério da Saúde; 2010.

7. Souza SNDHS, Mello DF, Ayres JRCM. $O$ aleitamento materno na perspectiva da vulnerabilidade programática e do cuidado. Cad Saúde Pública. 2013; 29(6):1186-94.

8. Charon JM. Symbolic Interactionism: an introduction, an interpretation, an integration. Englewood Cliffs: Prentice Hall; 2009.

9. Bardin L. Análise de conteúdo. Lisboa: Edições 70; 2009.

10. Minayo MCS. O desafio do conhecimento: pesquisa qualitativa em saúde. $12^{a}$ ed. São Paulo: Hucitec; 2010.

11. Carey MA, Asbury J. Focus group research. Walnut Creek: Left Coast Press; 2012.

12. Freire P. Pedagogia da esperança: um reencontro com a pedagogia do oprimido. $17^{\text {a }}$ ed. Rio de Janeiro: Paz e Terra; 2011.
13. Paula E, Campo J. História de vida: relação entre as vivências pessoais e profissionais na configuração das concepções e práticas em educação na infância. Interacções. 2011; (18):24-53.

14. Burgatti JC, Leonello VM, Bracialli LAD, Oliveira MAC. Estratégias pedagógicas para o desenvolvimento da competência ético-política na formação inicial em Enfermagem. Rev Bras Enferm. 2013; 66(2):282-6.

15. Abreu FCP, Fabbro MRC, Wernet M. Factors that intervene in exclusive breastfeeding: an integrative review. Rev Rene. 2013; 14(3):610-9.

16. Queiroz PA, Oliveira LRB, Martins CA. Elementos que interferem na amamentação exclusiva: percepções de nutrizes. Rev Salud Publica. 2009; 13(2):6-14.

17. Santos KK, Botelho ACF. Mitos que podem prejudicar o aleitamento materno em Perdizes, MG. Saud Pesq. 2010; 3(2):139-47.

18. Pena R, Silva GF. Experiências pessoais e suas implicações nas práticas de ensino. Antíteses. 2009; 2(3):105-20.

19. Sarti C. O lugar da família no Programa de Saúde da Família. In: Trad L, organizador. Família contemporânea e saúde: significados, práticas e políticas públicas. Rio de Janeiro: Fiocruz; 2010. p.91-103. 